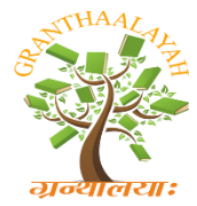

\author{
INTERNATIONAL JOURNAL OF RESEARCH - \\ GRANTHAALAYAH \\ A knowledge Repository
}

Science

\title{
FACTORS AFFECTING ADHERENCE TO RECOMMENDED MEDICATIONS AMONG PATIENTS WITH CHRONIC OBSTRUCTIVE PULMONARY DISEASE (COPD) IN A SELECTED TEACHING HOSPITAL, SRI LANKA
}

\author{
I.M.M. Dassanayaka ${ }^{1}$, K.K.V.P. Dayananda ${ }^{1}$, Thamara D. Amarasekara *1 \\ ${ }^{* 1}$ Department of Allied Health Sciences, Faculty of Medical Sciences, University of Sri \\ Jayawardenapura, Sri Lanka
}

\begin{abstract}
Background: This study was conducted to determine the prevalence of adherence and factors affecting adherence to recommended medications among patients with COPD in a selected teaching hospital, Sri Lanka.

Method: A descriptive cross-sectional design was used among conveniently selected $(\mathrm{n}=184)$ participants who attended to the Colombo South Teaching Hospital, Sri Lanka. Data were collected using a pre-tested $(n=10)$ interviewer-administered questionnaire and Morisky Green Levine Scale from January to March 2019.

Results: Most of the participants were male $(108,58.7 \%)$ and above 65 years old $(108,58.7 \%)$. Among all participants, 121 (65.8\%) adhered to the recommended medications for COPD, and 63 participants (34.2\%) were non-adhered. Demographic factors were not associated with adherence. Number of prescribed respiratory drug classes, number of respiratory medication on the last prescription, number of doses per day, vaccination (pneumococcal, influenza), using an electronic device to remember the time of administering medicine, $(\mathrm{p}<0.05)$ were significantly associated with adherence. According to the binary logistic regression analysis, clear and understandable written instructions in dispensing label $(\mathrm{p}<0.05)$ were significantly associated with adherence.

Conclusions: Most of the participants adhered to the recommended medications for COPD. Health education interventions might enhance the sustainability of adherence to recommended medication among patients with COPD.
\end{abstract}

Keywords: COPD; Adherence; COPD Medications; Sri Lanka.

Cite This Article: I.M.M. Dassanayaka, K.K.V.P. Dayananda, and Thamara D. Amarasekara. (2019). "FACTORS AFFECTING ADHERENCE TO RECOMMENDED MEDICATIONS AMONG PATIENTS WITH CHRONIC OBSTRUCTIVE PULMONARY DISEASE (COPD) IN A SELECTED TEACHING HOSPITAL, SRI LANKA.” International Journal of Research - Granthaalayah, 7(9), 16-29. https://doi.org/10.29121/granthaalayah.v7.i9.2019.553. 


\section{Introduction}

Chronic Obstructive Pulmonary Disease (COPD) is defined as a common, preventable, and treatable disease characterized by persistent respiratory symptoms and airflow limitation that is due to airway and alveolar abnormalities, usually caused by significant exposure to noxious particles or gases. The chronic airflow limitation that characterizes COPD is caused by a mixture of small airway disease (e.g., obstructive bronchiolitis), parenchymal destruction (emphysema) and the relative contributions, which vary from person to person [1].

According to the Burden of Obstructive Lung Diseases (BOLD) program and large-scale epidemiological studies, the global prevalence of COPD in the year 2010 was $11.7 \%$, and the estimated number of COPD cases was 384 million. Due to the increasing prevalence of smoking in developing countries and ageing populations in high-income countries, the prevalence of COPD is expected to rise over the next 30 years. Furthermore, there are around 3 million deaths annually caused by COPD and related respiratory conditions in 2010, which is expected to increase to 4.5 million by 2030 [2].

In China, the overall prevalence of diagnosed COPD was 5.9\%. The prevalence was significantly higher among men than in women and also among smokers than non-smokers [3]. According to the Symptom-based diagnosis in India, has shown that $7.7 \%$ overall COPD prevalence [4]. The overall prevalence of COPD in Sri Lanka was 10.5\%, and the prevalence of COPD among Sri Lankan adults is similar to global prevalence [5].

Environmental exposures and host factors are the main two types of risk factors for COPD. Tobacco smoking is the significant environmental exposures for COPD. Outdoor air pollution, indoor air pollution, infections, socioeconomic status and occupational exposures are the other environmental exposures for COPD. About host factors, genetic factors (alpha-1-antitrypsin deficiency), lung growth and development, age and gender, chronic bronchitis, asthma and airway hyperreactivity are main factors [1].

The management for COPD both pharmacological and non-pharmacological treatments are recommended. Bronchodilators ( $\$ 2$ agonists, antimuscarinic agents, methylxanthines and combine bronchodilator therapy), anti-inflammatory agents (glucocorticosteroids, inhaled corticosteroids), vaccines (Influenza and pneumococcal vaccines), alpha-1-antitrypsin augmentation therapy and vasodilators are the primary medications of pharmacological treatment [1]. Smoking cessation, rehabilitation, education, and self-management, oxygen therapy and hospice care, nutrition therapy and surgical treatments (bronchoscopic interventions, lung volume reduction surgery and lung transplantation) are also recommended as non-pharmacological treatments for patients with COPD [1].

The definition of adherence is the extent to which a person's behaviour-taking medication, following a diet, and executing lifestyle changes, corresponds with agreed recommendations from a healthcare provider. Factors affecting the COPD medication adherence can be classified under five dimensions as, patient-related factors, the health care team and system-related factors, social and economic factors, condition-related factors and therapy-related factors. [6] 
Non-adherence to the recommended medication can occur intentionally or unintentionally. Poor drug adherence results in reduced or lack of treatment benefits, additional unnecessary treatment, and decreased patient satisfaction with medical care [7]. Therefore, adherence to both pharmacological and non-pharmacological management is critical for optimal outcomes in patients with COPD. Proper medication adherence causes to decrease the number of hospitalizations and length of hospital stay among patients with chronic respiratory ailments and to gain maximum therapeutic outcome [8].

Though there is a significant number of a patient with COPD in Sri Lanka, there is not enough data regarding adherence to recommended COPD medications among patients with COPD. Therefore, it is essential to assess the factors affecting adherence to recommended medication among patients with COPD. The findings of this study may contribute to improving the adherence to recommended medication among patients with COPD in Sri Lanka.

\section{Materials and Methods}

A descriptive cross-sectional study conducted at the chest clinic and six medical wards at CSTH, Sri Lanka, which were selected for the study through convenience sampling. The study population was diagnosed patients with COPD, who entered to chest clinic and admitted to the six medical wards CSTH during the study period. Participants were aged above 18 years and diagnosed as a patient with COPD (as mentioned in their diagnosis card) and having COPD for at least six months. Participants had at least one spirometry value with a COPD diagnosis using the postbronchodilator forced expiratory volume in 1 second/forced vital capacity (FEV1/FVC) less than 0.70 criteria in the previous six months or diagnosed by the physician based on recommended clinical symptoms. Any participants with an acute or chronic condition that would limit the patient's ability to participate in the study (Eg: - Cognitively impaired patients, severally ill) was excluded from the study.

Patients were selected by consecutive sampling method for the study. On each clinic day, every patient with COPD, in the chest clinic and six medical wards, who satisfied the inclusion and exclusion criteria, were enrolled in the study. A note was made in the patient's clinic book/ medical records (BHT) to avoid re-recruiting of the same patient.

\subsection{Data Collection Instrument}

An aggregate of 208 patients with COPD was approached to take part in this cross-sectional study. From this 208, 18 patients refused to participate. The remaining 190 members were incorporated at baseline. Of these responses, 184 were usable, as six had to be removed as a result of not following inclusion and exclusion criteria. An interviewer-administered questionnaire and Morisky Green Levine Scale (MGLS) was used to assess the factors affecting medication adherence to prescribed COPD medication in patients with COPD.

The Morisky scale measures the adherence of the participants through four questions. Each "No" response to a question was given a score of one (01), and each 'Yes" response was given a score of zero (0). Participants were classified into two groups, as of adherence (score 3-4) and nonadherence (score 0-2). 
The questionnaire was initially created in English, and after that, it was translated into Sinhala \& Tamil. The questionnaire was pre-tested among ten patients with COPD who are not participated in this study to determine acceptability, feasibility, comprehensibility and appropriateness. Minor changes were done to the questionnaire after the pilot study.

\subsection{Data Analysis}

Pearson's Chi-square test and Fisher exact test with Statistical Package for Social Science version 21 (SPSS version 21) were used to analyzing the data. A binary logistic regression analysis was performed to identify the independent predictors of adherence.

\section{Results and Discussion}

\subsection{Results}

As shown in table 1 age, gender, marital status, education level and family income per month were the considered socio-demographic characteristics in this study. There were $108(58.7 \%)$ male participants and 76 (41.3\%) female participants. More than half of the participants were above 65 years old $(58.7 \%)$ and had primary education $(56 \%)$. Majority of the participants were married $(90.8 \%)$ and the monthly income of the family (LKR) of most of the participants was less than Rs. 25000 (40.2\%).

Table 1: Socio-demographic characteristics of participants $(\mathrm{N}=184)$

\begin{tabular}{|l|l|}
\hline Variable & Frequency (n) \\
\hline Age & \\
\hline $65>$ & $76(41.3)$ \\
\hline $65<$ & $108(58.7)$ \\
\hline Gender & \\
\hline Male & $108(58.7)$ \\
\hline Female & $76(41.3)$ \\
\hline Marital State & \\
\hline Single & $17(9.2)$ \\
\hline Married & $167(90.8)$ \\
\hline Education level & \\
\hline Primary & $103(56.0)$ \\
\hline Secondary/Higher level & $81(44.0)$ \\
\hline Employment & \\
\hline Student & $0(0.0)$ \\
\hline Employed & $70(38.0)$ \\
\hline Retired & $50(27.2)$ \\
\hline Unemployed & $64(34.8)$ \\
\hline Monthly income of the family (LKR) & \\
\hline $25000>$ & $74(40.2)$ \\
\hline $25001-35000$ & $59(32.1)$ \\
\hline $35001-45000$ & $29(15.8)$ \\
\hline $45001<$ & $22(12.0)$ \\
\hline
\end{tabular}

Values represent numbers of patients (percentage) as appropriate. 
As shown in table 2, current smoking status, amount of cigarettes used per day and exposure to dust particles are regarded as lifestyle-related characteristics in this study. Majority of participants were not current smokers $(86.4 \%)$. Seventy-one per cent of participants stated that they were on exposure to dust particles during most of the time of day $(70.7 \%)$.

Table 2: Lifestyle-related characteristics of participants $(\mathrm{N}=184)$

\begin{tabular}{|l|l|}
\hline Variable & Frequency (n) \\
\hline Current Smoking Status & \\
\hline Yes & $25(13.6)$ \\
\hline No & $159(86.4)$ \\
\hline Exposure to dust particles & \\
\hline Yes & $130(70.7)$ \\
\hline No & $54(29.3)$ \\
\hline
\end{tabular}

Values represent numbers of patients (percentage) as appropriate.

Medications and disease-related characteristics of the participants are shown in table 3. Most of the participants had less than 04 medications on their last prescription (91.3\%). All the participants used inhalers (100\%), and the majority of them used Metered-Dose Inhaler (MDI) as their type of inhaler $(83.2 \%)$. More than half of the patients were vaccinated (pneumococcal, influenza) (60.9\%). Almost all participants were counselled by the pharmacist regarding the prescribed medicines $(95.1 \%)$ and written instructions on the dispensing label were clear and understandable for the majority of the participants $(96.2 \%)$.

Table 3: Medications and disease-related characteristics of the participants. $(n=184)$

\begin{tabular}{|l|l|}
\hline Variable & Frequency (n) \\
\hline Time of diagnosed with COPD & \\
\hline 6 months -1 year & $47(25.5)$ \\
\hline 1 year - 3 years & $61(33.2)$ \\
\hline 3 years - 5 years & $33(17.9)$ \\
\hline More than 5 years & $43(23.4)$ \\
\hline Number of prescribed respiratory drug class & \\
\hline 1-2 drug classes & $50(27.2)$ \\
\hline 3-4 drug classes & $111(60.3)$ \\
\hline More than 5 drug classes & $23(12.5)$ \\
\hline Number of respiratory medications on last prescription & \\
\hline $1-2$ & $79(42.9)$ \\
\hline $3-4$ & $89(48.4)$ \\
\hline $5<$ & $16(8.7)$ \\
\hline Number of drug doses per day (related to respiratory indications) & \\
\hline $1-3$ & $63(34.2)$ \\
\hline $4-5$ & $72(39.1)$ \\
\hline $6<$ & $49(26.6)$ \\
\hline Vaccination (Pneumococcal, Influenza vaccines) & \\
\hline Vaccinated & $112(60.9)$ \\
\hline Non-vaccinated & $72(39.1)$ \\
\hline
\end{tabular}




\begin{tabular}{|l|l|}
\hline Usage of inhaler & \\
\hline Use an inhaler & $184(100.0)$ \\
\hline Do not use an inhaler & $0(0.0)$ \\
\hline Type of inhaler & \\
\hline MDI & $153(83.2)$ \\
\hline DPI & $16(8.7)$ \\
\hline Both & $15(8.2)$ \\
\hline Counselling by the prescriber on COPD & \\
\hline Yes & $144(78.3)$ \\
\hline No & 40 \\
\hline Clear counselling by the pharmacist regarding the prescribed medicines & \\
\hline Counselled & $175(95.1)$ \\
\hline Not counselled & $0(0.0)$ \\
\hline Not satisfied & $9(4.9)$ \\
\hline Clear and understandable written instructions on the dispensing label & \\
\hline Yes & $176(95.7)$ \\
\hline No & $8(4.3)$ \\
\hline Presence of co-morbidity conditions & \\
\hline Yes & $112(60.9)$ \\
\hline No & $72(39.1)$ \\
\hline $\begin{array}{l}\text { Mean number of medications on the last prescription } \\
\text { Mean number of drug doses per day } \\
\text { Mean number of prescribed drug classes }\end{array}$ & $2.90 \pm 1.141$ \\
\hline
\end{tabular}

Values represent numbers of patients (percentage) as appropriate.

Table 4: Characteristics related to medication taking and purchasing behaviour of the participants $(n=184)$

\begin{tabular}{|l|l|}
\hline Variable & Frequency (n) \\
\hline The most preferred way to take medication & \\
\hline As inhaler & $74(40.2)$ \\
\hline As tablets/pills & $15(8.2)$ \\
\hline Type of medicine is not a problem & $95(51.6)$ \\
\hline Using an electronic device to remember the time of administering medicine & \\
\hline Yes & $11(6.0)$ \\
\hline No & $173(94.0)$ \\
\hline
\end{tabular}

Values represent numbers of patients (percentage) as appropriate.

Prevalence of Adherence and Non-Adherence to Recommended COPD Medication

Of the 184 participants, the prevalence of adherence to recommended medications among patients with COPD was $65.8 \%(n=121)$, and $34.2 \%(n=63)$ of prevalence was recorded for non-adherence Table 5. 
Table 5: Prevalence of adherence and non-adherence to recommended medications for COPD

\begin{tabular}{|l|l|}
\multicolumn{2}{c}{$(\mathrm{n}=184)$} \\
\hline Adherence Level & Frequency \\
\hline Adherence & $121(65.8)$ \\
\hline Non-adherence & $63(34.2)$ \\
\hline
\end{tabular}

Values represent numbers of patients (percentage) as appropriate.

Factors Affecting Adherence to Recommended Medications Among Participants with COPD No significant association was observed between adherence group and demographic variables including age, gender, marital status, educational level, employment and monthly income of the family (LKR) (Table 8).

Table 6: Demographic factors affecting adherence to recommended medications for COPD

\begin{tabular}{|l|l|l|l|}
\hline Variable & $\begin{array}{l}\text { Adherent } \\
(\mathbf{n = 1 2 1})\end{array}$ & $\begin{array}{l}\text { Non-adherent } \\
(\mathbf{n = 6 3})\end{array}$ & P value \\
\hline Age & $53(69.7)$ & $23(30.3)$ & 0.340 \\
$65>$ & $68(63.0)$ & $40(37.0)$ & \\
$65<$ & $75(69.4)$ & $33(30.6)$ & 0.209 \\
\hline Gender & $46(60.5)$ & $30(39.5)$ & \\
Male & $11(64.6)$ & $6(35.3)$ & 0.923 \\
Female & $110(65.9)$ & $57(34.1)$ & \\
\hline Marital status & & & \\
Single & $66(64.1)$ & $37(35.9)$ & 0.587 \\
Married & $55(67.9)$ & $26(32.1)$ & \\
\hline Educational level & & & \\
Primary education only & $0(0)$ & $0(0)$ & 0.806 \\
Secondary/higher education & $47(67.1)$ & $23(32.9)$ & \\
\hline Employment & $31(62.0)$ & $19(38.0)$ & \\
Student & $43(67.2)$ & $21(32.8)$ & \\
Employed & & & \\
Retired & & & \\
Unemployed & $46(62.2)$ & $28(37.8)$ & \\
\hline Monthly income of the family (LKR) & $43(72.9)$ & $16(27.1)$ & \\
25000> & $21(72.4)$ & $8(27.6)$ & $11(50.0)$ \\
25001-35000 & $11(50.0)$ & \\
35001-45000 & & & \\
45001< & & \\
\hline
\end{tabular}


Table 7: Other factors affecting adherence to recommended medications for COPD (N=184)

\begin{tabular}{|c|c|c|c|c|c|}
\hline \multirow[t]{2}{*}{ Variable } & \multicolumn{2}{|l|}{$\begin{array}{l}\text { Adherent } \\
(\mathbf{n}=121)\end{array}$} & \multicolumn{2}{|c|}{$\begin{array}{l}\text { Non-adherent } \\
(\mathbf{n = 6 3 )}\end{array}$} & \multirow[t]{2}{*}{$\begin{array}{l}P \\
\text { value }\end{array}$} \\
\hline & Frequency & Percentage & Frequency & Percentage & \\
\hline $\begin{array}{l}\text { Exposure for Dust Particles } \\
\text { Yes } \\
\text { No }\end{array}$ & $\begin{array}{l}37 \\
84 \\
\end{array}$ & $\begin{array}{l}68.5 \\
64.6 \\
\end{array}$ & $\begin{array}{l}46 \\
17 \\
\end{array}$ & $\begin{array}{l}35.4 \\
31.5\end{array}$ & 0.611 \\
\hline $\begin{array}{l}\text { Time of diagnosis of COPD } \\
0.5-1 \\
1-3 \\
3-5 \\
5<\end{array}$ & $\begin{array}{l}32 \\
41 \\
24 \\
24\end{array}$ & $\begin{array}{l}68.1 \\
67.2 \\
72.7 \\
55.8\end{array}$ & $\begin{array}{l}15 \\
20 \\
9 \\
19\end{array}$ & $\begin{array}{l}31.9 \\
32.8 \\
27.3 \\
44.2\end{array}$ & 0.428 \\
\hline $\begin{array}{l}\text { Smoking } \\
\text { Yes } \\
\text { No }\end{array}$ & $\begin{array}{l}15 \\
106 \\
\end{array}$ & $\begin{array}{l}60.0 \\
66.7 \\
\end{array}$ & $\begin{array}{l}10 \\
53 \\
\end{array}$ & $\begin{array}{l}40.0 \\
33.3 \\
\end{array}$ & 0.514 \\
\hline $\begin{array}{l}\text { Number of prescribed } \\
\text { respiratory drug classes } \\
\text { 1-2 drug class } \\
\text { 3-4 drug classes } \\
\text { 5< drug classes }\end{array}$ & $\begin{array}{l}41 \\
71 \\
9\end{array}$ & $\begin{array}{l}82 \\
64 \\
39.1\end{array}$ & $\begin{array}{l}9 \\
40 \\
14\end{array}$ & $\begin{array}{l}18 \\
36 \\
60.9\end{array}$ & 0.001 \\
\hline 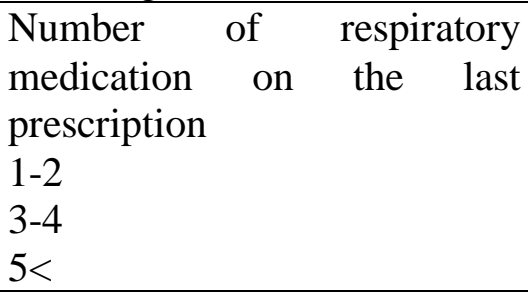 & $\begin{array}{l}62 \\
55 \\
04\end{array}$ & $\begin{array}{l}78.5 \\
61.8 \\
25.0\end{array}$ & $\begin{array}{l}17 \\
34 \\
12\end{array}$ & $\begin{array}{l}21.5 \\
38.2 \\
75.0\end{array}$ & 0.000 \\
\hline $\begin{array}{l}\text { Number of doses per day } \\
\text { (related only to respiratory } \\
\text { indications) } \\
1-3 \\
4-5 \\
\text { More than } 6\end{array}$ & $\begin{array}{l}47 \\
50 \\
24\end{array}$ & $\begin{array}{l}74.6 \\
69.4 \\
49\end{array}$ & $\begin{array}{l}16 \\
22 \\
25\end{array}$ & $\begin{array}{l}25.4 \\
30.6 \\
51\end{array}$ & 0.013 \\
\hline $\begin{array}{l}\text { Vaccination (Pneumococcal, } \\
\text { Influenza vaccines) } \\
\text { Vaccinated } \\
\text { Non-vaccinated }\end{array}$ & $\begin{array}{l}80 \\
41\end{array}$ & $\begin{array}{l}71.4 \\
56.9\end{array}$ & $\begin{array}{l}32 \\
31\end{array}$ & $\begin{array}{l}28.6 \\
43.1\end{array}$ & 0.043 \\
\hline $\begin{array}{l}\text { Usage of Inhaler } \\
\text { Yes } \\
\text { No }\end{array}$ & $\begin{array}{l}121 \\
0\end{array}$ & $\begin{array}{l}65.8 \\
0\end{array}$ & $\begin{array}{l}63 \\
0\end{array}$ & $\begin{array}{l}34.2 \\
0\end{array}$ & * \\
\hline $\begin{array}{l}\text { Type of Inhaler } \\
\text { MDI } \\
\text { DPI } \\
\text { Both } \\
\end{array}$ & $\begin{array}{l}106 \\
08 \\
07\end{array}$ & $\begin{array}{l}69.3 \\
50 \\
46.7\end{array}$ & $\begin{array}{l}47 \\
08 \\
08\end{array}$ & $\begin{array}{l}30.7 \\
50 \\
53.3\end{array}$ & 0.081 \\
\hline $\begin{array}{l}\text { The most preferred way to take } \\
\text { medication }\end{array}$ & $\begin{array}{l}52 \\
06 \\
\end{array}$ & $\begin{array}{l}70.3 \\
40\end{array}$ & 22 & $\begin{array}{l}29.7 \\
60 \\
\end{array}$ & 0.078 \\
\hline
\end{tabular}




\begin{tabular}{|c|c|c|c|c|c|}
\hline $\begin{array}{l}\text { As inhaler } \\
\text { As tablets/pills } \\
\text { Medication type is not a } \\
\text { problem }\end{array}$ & 63 & 66.3 & $\begin{array}{l}09 \\
32\end{array}$ & 33.7 & \\
\hline $\begin{array}{l}\text { Counselling by the prescriber } \\
\text { on COPD } \\
\text { Yes } \\
\text { No }\end{array}$ & $\begin{array}{r}96 \\
25\end{array}$ & $\begin{array}{l}66.7 \\
62.5\end{array}$ & $\begin{array}{l}48 \\
15\end{array}$ & $\begin{array}{l}33.3 \\
37.5\end{array}$ & 0.623 \\
\hline $\begin{array}{l}\text { Using an electronic device to } \\
\text { remember the time of } \\
\text { administering medicine } \\
\text { Yes } \\
\text { No }\end{array}$ & $\begin{array}{l}04 \\
117\end{array}$ & $\begin{array}{l}36.4 \\
67.6\end{array}$ & $\begin{array}{l}07 \\
56\end{array}$ & $\begin{array}{l}63.6 \\
32.4\end{array}$ & $0.048^{\mathrm{a}}$ \\
\hline $\begin{array}{l}\text { Clear counselling by the } \\
\text { pharmacist regarding the } \\
\text { medicines } \\
\text { Yes } \\
\text { No } \\
\text { Not sufficient }\end{array}$ & $\begin{array}{l}117 \\
0 \\
4\end{array}$ & $\begin{array}{l}66.9 \\
0 \\
44.7\end{array}$ & $\begin{array}{l}58 \\
00 \\
05\end{array}$ & $\begin{array}{l}33.1 \\
00 \\
55.6\end{array}$ & $0.278^{\mathrm{a}}$ \\
\hline $\begin{array}{l}\text { Clear and understandable } \\
\text { written instructions in } \\
\text { dispensing the label } \\
\text { Yes } \\
\text { No }\end{array}$ & $\begin{array}{l}120 \\
01\end{array}$ & $\begin{array}{l}68.2 \\
12.5\end{array}$ & $\begin{array}{l}56 \\
07\end{array}$ & $\begin{array}{l}31.8 \\
87.5\end{array}$ & $0.003^{\mathrm{a}}$ \\
\hline $\begin{array}{l}\text { Presence of co-morbidity } \\
\text { conditions } \\
\text { Yes } \\
\text { No }\end{array}$ & $\begin{array}{l}75 \\
46 \\
\end{array}$ & $\begin{array}{l}67 \\
63.9 \\
\end{array}$ & $\begin{array}{l}37 \\
26 \\
\end{array}$ & $\begin{array}{l}33 \\
36.1 \\
\end{array}$ & 0.668 \\
\hline
\end{tabular}

*No statistics are computed because the type of pharmacy that the patient visits generally and usage of inhaler is a constant.

\section{Values derived from Fisher's exact test}

Number of prescribed respiratory drug classes, number of respiratory medication on last prescription, number of doses per day (related to respiratory indications), vaccination (pneumococcal, influenza), using electronic device to remember the time of administering medicine and clear and understandable written instructions in dispensing label $(\mathrm{p}<0.05)$ were significantly associated with adherence group. Table 8 presents the results of the binary logistic regression model. Number of prescribed respiratory drug classes, number of respiratory medications on the last prescription, number of doses per day (related only to respiratory indications), using an electronic device to remember the time of administering medicine and clear, understandable written instructions in dispensing label were analysed as independent variables. Among the above factors, only clear and understandable written instructions in dispensing label $(\mathrm{p}=0.014)$ were given a significant association with adherence to recommended medication for COPD in a binary logistic regression model test. These variables together explained $22.3 \%$ of the variance of adherence (Nagelkerke $R^{2}=0.223$ ). 
Table 8: Binary logistic regression model predicting adherence to recommended medication for

\begin{tabular}{|l|l|l|l|}
\hline Variable COPD (N=184) & P value \\
\hline Number of prescribed respiratory drug classes & $\begin{array}{l}\text { Odds } \\
\text { ratio }\end{array}$ & $\begin{array}{l}\text { Confidence } \\
\text { Interval (95\%) }\end{array}$ & 1.095 \\
\hline $\begin{array}{l}\text { Number of respiratory medication on the last } \\
\text { prescription }\end{array}$ & 2.588 & $0.428-2.797$ & 0.850 \\
\hline $\begin{array}{l}\text { Number of doses per day (related to } \\
\text { respiratory indications) }\end{array}$ & 0.948 & $0.500-1.801$ & 0.081 \\
\hline $\begin{array}{l}\text { Using an electronic device to remember the time } \\
\text { of administering medicine }\end{array}$ & 0.401 & $0.101-1.592$ & 0.194 \\
\hline $\begin{array}{l}\text { Clear and understandable written instructions } \\
\text { in dispensing the label }\end{array}$ & 15.631 & $1.730-141.22$ & $0.014^{*}$ \\
\hline
\end{tabular}

According to the binary logistic regression analysis among above-evaluated variables, only clear and understandable written instructions in dispensing label $(\mathrm{p}<0.05)$ were given a significant association with adherence to recommended medication for COPD.

\subsection{Discussion}

\section{Prevalence of Adherence to Recommended COPD Medications}

The present study indicated that $65.4 \%(n=121)$ rate of adherence and $34.6 \%(n=63)$ rate of nonadherence; therefore, most of the participants in this study adhered with recommended medication for COPD. Similar findings were reported in the study conducted by Khdour et al. (2012) [9]. Among 173 participants from their study, less than one-third of the participant $(29.5 \%)$ had been presented in the low medication adherence category, and others were under high adherence category. In both studies, the Morisky Green Levine Scale was used to assess the level of adherence of participants with COPD. In a similar study $(\mathrm{n}=170)$ conducted in Hungaria by using Morisky Medication Adherence Scale-4 (MMAS-4), more than half of the participants (58.2\%) had reported optimal adherence with medication for COPD [10]. Above studies had shown that the proportion of adherence was higher than the proportion of non-adherence of the participants, to the recommended medication for COPD.

Another study had been conducted by Oca et al. (2016), to find out adherence to inhaler therapy of participants with COPD from seven Latin American countries. In this study, Morisky Medication Adherence Scale-8 (MMAS-8) questionnaires and Test of Adherence to Inhalers (TAI) had been used to assess the adherence level of the participants. Findings of the study were revealed that participants had good $(54.1 \%)$, intermediate $(26.5 \%)$, and poor $(19.4 \%)$ adherence based on the TAI questionnaire and they had high (51\%), medium $(29.1 \%)$, and low adherence (19.9\%) based on the MMAS-8 questionnaire [11].

In an observational retrospective study conducted in the USA, adherence had been measured in terms of the proportion of days covered over a 365-days following the first COPD prescription among 14,117 patients and had found that $79.2 \%$ were non-adherent to the recommended COPD medications, which means that non-adherence proportion is higher than adherence proportion [12]. 


\section{Factors Affecting Adherence To Recommended COPD Medications}

According to the results of the present study, number of prescribed respiratory drug classes for the treatment of COPD, number of respiratory drugs on the last prescription, number of daily drug doses per day (related to respiratory indications) and vaccination (Pneumococcal, Influenza vaccines) were significantly associated with adherence to recommended medication for COPD. Furthermore, using an electronic device to remember the time of administering medicine and clear and understandable written instructions in dispensing label were significantly associated with adherence to medications for COPD.

Similar study findings were reported in a study conducted by Agh et al. (2011), that number of prescribing respiratory drugs and doses per day were associated with adherence, and both were inversely related to the adherence of medication for COPD. The present study also reported that a number of prescribed respiratory drug classes for treatment to COPD, the number of respiratory drugs on last prescription and number of daily respiratory drug doses per day were significantly associated with adherence. The patient should involve in decision making regarding their medication whenever possible. Reducing dosing frequency as appropriate and usage of fixed combination therapy when applicable may simplify the regimen and enhance adherence to recommended medication for COPD [10].

Vaccination (pneumococcal, influenza) was one of the variables that were found to be significantly associated with the adherence status of the participants in this study. Pereza et al. (2011) had conducted a cross-sectional study on assessing barriers to adherence to COPD guidelines among primary care providers in New York City. This study was found that adherence of participants was higher $(90 \%)$ to the influenza vaccination than other medication for COPD, and routinely, vaccination may enhance adherence to recommended medication for COPD [13].

Patients had experienced difficulties in adhering to their long-term medications because of barriers such as forgetfulness [14]. A meta-analysis conducted in 2016, on mobile telephone text messaging for medication adherence in chronic disease, had revealed that text messaging significantly improved medication adherence to taking medications among middle-aged patients with chronic disease (odds ratio, 2.11; 95\% CI, 1.52-2.93; P <0.001) [15]. In the present study, using an electronic device such as mobile phones or alarms, to remember the time of administering medicine, was significantly associated with adherence for the recommended medication of COPD. Among patients who have not used an electronic device to remember the time of administering medicine, $32 \%$ was non-adherent to the treatments. Therefore, there was a significant relationship between using an electronic device to remember the time of administering medicine and adherence to the medication among patients with COPD.

Explain vital information of the medicine (what, why, when, how, and how long) and communicating with the patient when prescribing or dispensing a medicine may influence the medication adherence [16]. According to the results obtained from the present study, clear and understandable written instructions in dispensing label had shown a significant association with participant's adherence for recommended medicine. Furthermore, clear and understandable written instructions in dispensing label were the only factor that shows a significant association in the binary logistic regression test. 


\section{Factors Which Have No Significant Association With Adherence Level}

With regards to the demographic data of the present study, which included gender, age, marital status, employment and monthly income of the family, no significant association was found with adherence to recommended medication for COPD. Similar results were shown in a study conducted in Northern Ireland with similar Morisky scale [9]. In both studies, demographical variables were not significantly associated with adherence. According to a study conducted in Hungaria, adherence to respiratory therapy was associated with age, but gender was not significantly associated with adherence [10]. According to a study conducted in Poland, sex, education and occupation did not influence the adherence for treatment of COPD [17].

In contrast with the present study, a Hungarian study has revealed that adherence to respiratory therapy was associated with current smoking status [10]. More than half of the participants in the present study had co-morbidity conditions (60.9\%), and no significant association was identified between adherence and the presence of co-morbidity conditions. Presence of co-morbid illnesses among 154 outpatients in COPD clinic at the Mater Hospital, Northern Ireland was associated with medication adherence in the study conducted by Khdour et al. [9]. Contrast findings were reported in the present study.

Present study results showed that the most preferred way to take medications had no significant association with adherence level and way of taking medication was not a problem for more than half of participants (51.6\%). In a previous study conducted by Miravitlles et al. in Spain, (2018) using internet-based, self-administered questionnaire, most of the study participants prioritized the selection of the drug (tablets or pills) over the devices [18].

A descriptive cross-sectional study conducted by Samankantha et al (2017) to identify the risk factors for COPD in central Sri Lanka has revealed that the majority of participants were smokers and also had exposure to one or more other known risk factors (e.g., indoor air pollution, agricultural dust exposures, timber dust, and industrial dust exposures). The highest number of participants had indoor air pollution as the leading risk factor other than smoking in their study. The researchers were suggested that exposure to multiple risk factors may have contributed to the majority having severe COPD [19]. Based on the results obtained from the present study, exposure to dust particles was not significantly associated with adherence to recommended medication for COPD; however, most of the participants had been exposed to dust particles.

\section{Limitations}

There were a few limitations in this study. Finding of this study cannot be generalized, as only one hospital was selected to gather data. However, the outcomes of this study can give vital information that can be helpful in planning and performing further investigations.

\section{Conclusions and Recommendations}

This study was conducted in Colombo South Teaching Hospital using 184 samples to determine the prevalence of adherence and factors affecting adherence to recommended medications among patients with COPD. 
Most of the participants were above 65 years. High proportions of male participants were there. According to 4 items MGLS, the proportion of adherence to the medicine of COPD was higher than the proportion of non-adherence.

Number of prescribed respiratory drug classes for COPD, number of respiratory drugs on last prescription, number of daily drug doses per day (related to respiratory indications) and vaccination (Pneumococcal, Influenza vaccines), using electronic device to remember the time of administering the medicine and clear and understandable written instructions in Therefore, simplify the dosing regimens by prescribing fewer frequency medicines and using dispensing label were the factors affecting adherence in this study. Combination drug therapies (Salmeterol/Fluticasone combination) as appropriate, routine vaccination, provide clear and understandable writing information on dispensing labels, useful patient-clinician interaction is critical for optimal medication adherence in patients with COPD.

\section{Recommendations}

Health care professionals should provide more effective health education interventions to enhance the sustainability of adherence to recommended medication among patients with COPD. Further studies should be conducted in other health care settings in Sri Lanka to generalizing the findings. Further studies should conduct on patients' involvement in decision making regarding their medication by enhancing effective patient-clinician interaction.

\section{References}

[1] Global Initiative for Chronic Obstructive Lung Disease (2017) Journal of Cardiopulmonary Rehabilitation. doi: 10.1097/00008483-200207000-00004.

[2] Global Initiative for Chronic Obstructive Lung Disease (2018) Global Initiative for Chronic Obstructive Lung Disease, Inc. doi: http://dx.doi.org/10.1164/rccm.201701-0218PP.

[3] $\mathrm{Xu}, \mathrm{F}$. et al. (2005) 'Prevalence of physician-diagnosed COPD and its association with smoking among urban and rural residents in regional mainland China', Chest. doi: 10.1378/chest.128.4.2818.

[4] Global surveillance, prevention and control of chronic respiratory diseases (2007). doi: ISBN 978 9241563468.

[5] Amarasiri, L. et al. (2017) 'The prevalence of Chronic Obstructive Pulmonary Disease (COPD) in Sri Lanka: outcome of the BOLD study'. Available at: http://erj.ersjournals.com/content/50/suppl_61/PA1212.

[6] World Health Organization (2003) 'Adherence to long-term therapies: Evidence for action', European Journal of Cardiovascular Nursing, 2(4), p. 323. doi: 10.1016/S1474-5151(03)00091-4.

[7] Tabor, P. A. and Lopez, D. A. (2004) 'Comply with Us: Improving Medication Adherence', Journal of Pharmacy Practice, 17(3), pp. 167-181. doi: 10.1177/0897190004264816.

[8] David, J. G., Kong, C. M. and Stewart, K. (2007) Adherence to disease management programs in patients with COPD, International Journal of COPD.

[9] Khdour, M. R. et al. (2012) 'Potential risk factors for medication non-adherence in patients with chronic obstructive pulmonary disease (COPD)', European Journal of Clinical Pharmacology. doi: 10.1007/s00228-012-1279-5.

[10] Agh, T., Inotai, A. and Meszaros, A. (2011) 'Factors associated with medication adherence in patients with chronic obstructive pulmonary disease', Respiration. doi: 10.1159/000324453.

[11] Oca, M. M. de et al. (2016) 'Adherence to inhaled therapies of COPD patients from seven Latin American countries: The LASSYC study', PLoS ONE. doi: 10.1371/journal. 
[12] Dhamane, A. D. et al. (2016) 'Association between adherence to medications for COPD and medications for other chronic conditions in COPD patients', International Journal of COPD. doi: 10.2147/COPD.S114802.

[13] Perez, X., Wisnivesky, J.P., Lurslurchachai, L., Kleinman, L.C. and Kronish, I.M., 2012. 'Barriers to adherence to COPD guidelines among primary care providers'. Respiratory medicine, 106(3), pp.374-381.

[14] Vervloet, M., Linn, A. J., van Weert, J. C., de Bakker, D. H., Bouvy, M. L., \& van Dijk, L. (2012). 'The effectiveness of interventions using electronic reminders to improve adherence to chronic medication: a systematic review of the literature'. Journal of the American Medical Informatics Association: JAMIA, 19(5), 696-704. doi:10.1136/amiajnl-2011-000748

[15] Thakkar, J., Kurup, R., Laba, T.L., Santo, K., Thiagalingam, A., Rodgers, A., Woodward, M., Redfern, J. and Chow, C.K., 2016. Mobile telephone text messaging for medication adherence in chronic disease: a meta-analysis. JAMA internal medicine, 176(3), pp.340-349.

[16] Jimmy, B. and Jose, J., 2011. Patient medication adherence: measures in daily practice: Oman medical journal, 26(3), p.155.

[17] Wiśniewski, D. et al. (2014) 'Factors influencing adherence to treatment in COPD patients and its relationship with disease exacerbations', Pneumonologia i Alergologia Polska, 82(2), pp. 96-104. doi: 10.5603/PiAP.2014.0015.

[18] Miravitlles, M. et al. (2018) 'Factors affecting the selection of an inhaler device for COPD and the ideal device for different patient profiles. Results of EPOCA Delphi consensus', Pulmonary Pharmacology and Therapeutics. Elsevier Ltd, 48, pp. 97-103. doi: 10.1016/j.pupt.2017.10.006.

[19] Samankantha, S. et al. (2017) 'Descriptive analysis of risk factors in a COPD cohort in central Sri Lanka', Respirology. doi: 10.1111/resp.13207_421.

\footnotetext{
*Corresponding author.

E-mail address: thamaraamarasekara@ yahoo.com/thamara@ sjp.ac.lk
} 